\title{
An infected urachal cyst is a rare differential diagnosis for an acute abdomen in adult female: a case report
}

\author{
Ramesh Bettaiah $^{1}$, Shraddha Neminath Kurkuri ${ }^{1}$, M. Chandramouli ${ }^{2}$ \\ ${ }^{1}$ Department of Gynaecological Endoscopy and Infertility, Dr Ramesh Hospital, Bangalore, Karnataka, India \\ ${ }^{2}$ Department of Surgery, Dr Ramesh Hospital, Bangalore, Karnataka, India
}

Received: 29 February 2016

Revised: 02 March 2016

Accepted: 30 March 2016

*Correspondence:

Dr. Shraddha Neminath Kurkuri,

E-mail: www.snk3061988@gmail.com

Copyright: ( ) the author(s), publisher and licensee Medip Academy. This is an open-access article distributed under the terms of the Creative Commons Attribution Non-Commercial License, which permits unrestricted non-commercial use, distribution, and reproduction in any medium, provided the original work is properly cited.

\begin{abstract}
An infected urachal cyst is one of a spectrum of presentations of urachal pathology, all of which are rare in adulthood. Patients tend to present in a heterogeneous fashion, making diagnosis difficult. A 45-year old lady presented with sudden onset of lower abdominal pain and fever since 10 days. There was tenderness and focal rigidity in the right iliac fossa. Abdominal ultrasonography revealed suprapubic collection with mixed echogenecity. On diagnostic laparoscopy; urachal abscess was confirmed and excised. Urachal disease is usually detected in infancy and childhood. Infection is the usual mode of presentation amongst adults otherwise the condition usually remains asymptomatic. Diagnosis is often made after exploratory laparotomy or laparoscopy. Ultimately, surgical intervention is the treatment of choice. Complete excision is important because malignant degeneration of the remnant is possible. In cases where a pre-operative diagnosis has been made, a staged approach with antibiotics followed by surgery has been recommended.
\end{abstract}

Keywords: Urachus, Urachal cyst, Abscess, Adult

\section{INTRODUCTION}

An infected urachal cyst is one of a spectrum of presentations of urachal anomaly, all of which are rare in adulthood. Patients may present in a heterogeneous fashion, making diagnosis difficult. ${ }^{1}$ We report a rare case of an infected urachal cyst presenting as acute abdomen in a middle aged women.

\section{CASE REPORT}

A 45-year old lady presented with lower abdominal pain and fever since 10 days. On examination, she was looking unwell and had tachycardia with temperature of $101^{\circ} \mathrm{F}$. There was tenderness and focal rigidity in right iliac fossa. An abdominal \& pelvic ultrasonography (Figure 1a) revealed suprapubic cystic lesion with internal mixed echogenecity.

We performed exploratory laparoscopy. The diagnosis of urachal abscess was confirmed $\&$ it was completely excised (Figure 1b, 1c). Under cystoscopic guidance, bladder wall was also repaired in two layers. She was given antibiotics peri-operatively for 7 days. She had an uneventful recovery \& was discharged on day 2 . The pathological report was consistent with urachal cyst abscess.

\section{DISCUSSION}

Urachus (median umbilical ligament), developmentally is the upper part of the bladder, both of which arise from ventral part of cloaca and allantois. Descent of bladder from 5th month of development into foetal pelvis pulls urachus with it resulting in the formation of the urachal canal. ${ }^{2}$ This canal progressively obliterates during foetal life, forming a fibrous tract in early adult life with no function. Incomplete regression of the urachal lumen results in several anomalies like (Figure 1d): urachal sinus, urachal cyst, patent urachus and urachal diverticulum. ${ }^{3}$ Histologically, it is composed of 3 layers; 
an innermost layer of modified transtitional epithelium, a middle layer of fibro connective tissue and an outer layer of smooth muscle continuous with the detrusor. ${ }^{2}$

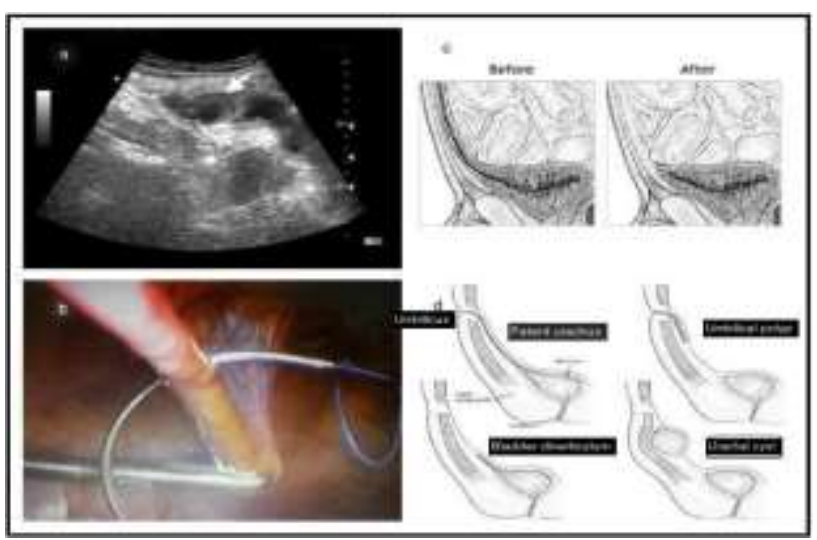

Figure 1: A; Urachal abscess in ultrasound abdomen and pelvis: suprapubic cystic lesion with internal mixed echogenecity (longitudinal section), B;

Laparoscopic excision of urachal abscess, C; Before and after urachal cyst abscess excision, D; Types of urachal anomalies.

Urachal disease is usually detected in infancy and childhood, it is rare in adults. Yiee et al reported 2 cases per 100,000 hospital admissions in adults. ${ }^{4}$ Infection is the usual mode of presentation amongst adults otherwise the condition usually remains asymptomatic. It is more common in men than women. Patients with infected urachal cysts can present with a wide range of symptoms like abdominal pain, fever, umbilical discharge and feeling of a midline mass. Owing to the low incidence and heterogeneous presentation patients can be misdiagnosed. ${ }^{1}$

Diagnosis is often confirmed following exploratory laparotomy or laparoscopy. Complications include sepsis, fistula formation \& rupture leading to peritonitis. Necrotizing fasciitis has also been reported as a rare complication of an infected urachal cyst. ${ }^{5}$ Important organisms implicated are Escherichia coli, Enterococcus faecium \& Klebsiella pneumonia. Ultrasound, computed tomography and magnetic resonance imaging will help in the diagnosis. Ultrasound scan can assist to make diagnosis in $77 \%$ of patients. ${ }^{6}$

In cases where a pre-operative diagnosis has been made, a two-staged approach with antibiotics followed by surgery has been recommended. ${ }^{6}$ Ultimately, surgical intervention is the treatment of choice. Complete excision is important because malignant degeneration of the remnant is possible. ${ }^{1}$ Malignant degeneration of urachal remnants occurs more frequently in middle aged and older people. ${ }^{7}$ It has a course that can be considerably worse than that of primary bladder adenocarcinomas. ${ }^{8}$ Traditionally, open excision has been the approach of choice; however, a laparoscopic approach is also an attractive alternative. ${ }^{9}$ Indeed, it has been suggested that endoscopy be the approach of choice because of its acknowledged advantages, including minimal trauma, superb visualization, low incidence of complications, reduced chances of adhesion formation, rapid recovery \& cosmetic effect. ${ }^{9}$

\section{CONCLUSION}

Infection of urachal cyst in adults is a very rare but important differential diagnosis for acute pain abdomen. Complete surgical excision is the treatment of choice due to the risk of malignant transformation. The laparoscopic excision appears to be safe and effective alternative to laparotomy. It provides better access to the bladder dome in contrast to classical open surgical incisions. It also yields good long-term cosmetic results. We recommend a 2 stage treatment with a combination of broad spectrum antibiotics or incision and drainage, followed by interval excision after resolution of sepsis.

Funding: No funding sources

Conflict of interest: None declared

Ethical approval: Not required

\section{REFERENCES}

1. Risher WH, Sarda A, Bolton J. Urachal abnormalities in adults: the Ochsner experience. Southern Medical Journal. 1990;83:1036-9.

2. Begg RC. The urachus: its anatomy, histology and development. Journal of Anatomy. 1930;64:170-83.

3. Mesrobian HG, Zacharias A, Balcon AH, Cohen RD. Ten years of experience with isolated urachal anomalies in children. J Urol. 1997;158(3 Pt 2):1316-8.

4. Yiee JH, Garcia N, Baker LA, Barber R, Snodgross WT, Wilcox DT. A diagnostic algorithm for urachal anomalies. J Pediatr Urol. 2007;3:500-4.

5. Ekwueme KC, Parr NJ. Infected urachal cyst in an adult: a case report and review of the literature. Cases Journal. 2009;2:6422.

6. Yoo KH, Lee SJ, Chang SG. Treatment of infected urachal cysts. Yonsei Medical Journal. 2006;47:4237.

7. Ueno T, Hashimoto H, Yokoyama H, Ito M, Kouda K. Urachal anomalies: ultrasonography and management. J Pediatr Surg. 2003;38:1203.

8. Beck AD, Gaudin JH, Bonhan GD. Carcinoma of urachus. Br J Urol. 1970;42:555-62.

9. Groot-Wassink T, Deo H, Charfare H, Foley R. Laparoscopic excision of the urachus. Surgical Endoscopy. 2000;14:680-1.

Cite this article as: Bettaiah R, Kurkuri SN,

Chandramouli M. An infected urachal cyst is a rare differential diagnosis for an acute abdomen in adult female: a case report. Int J Reprod Contracept Obstet Gynecol 2016;5:1655-6. 